\title{
O SISTEMA DE RECOMPENSA NA EMPRESA DO FUTURO
}

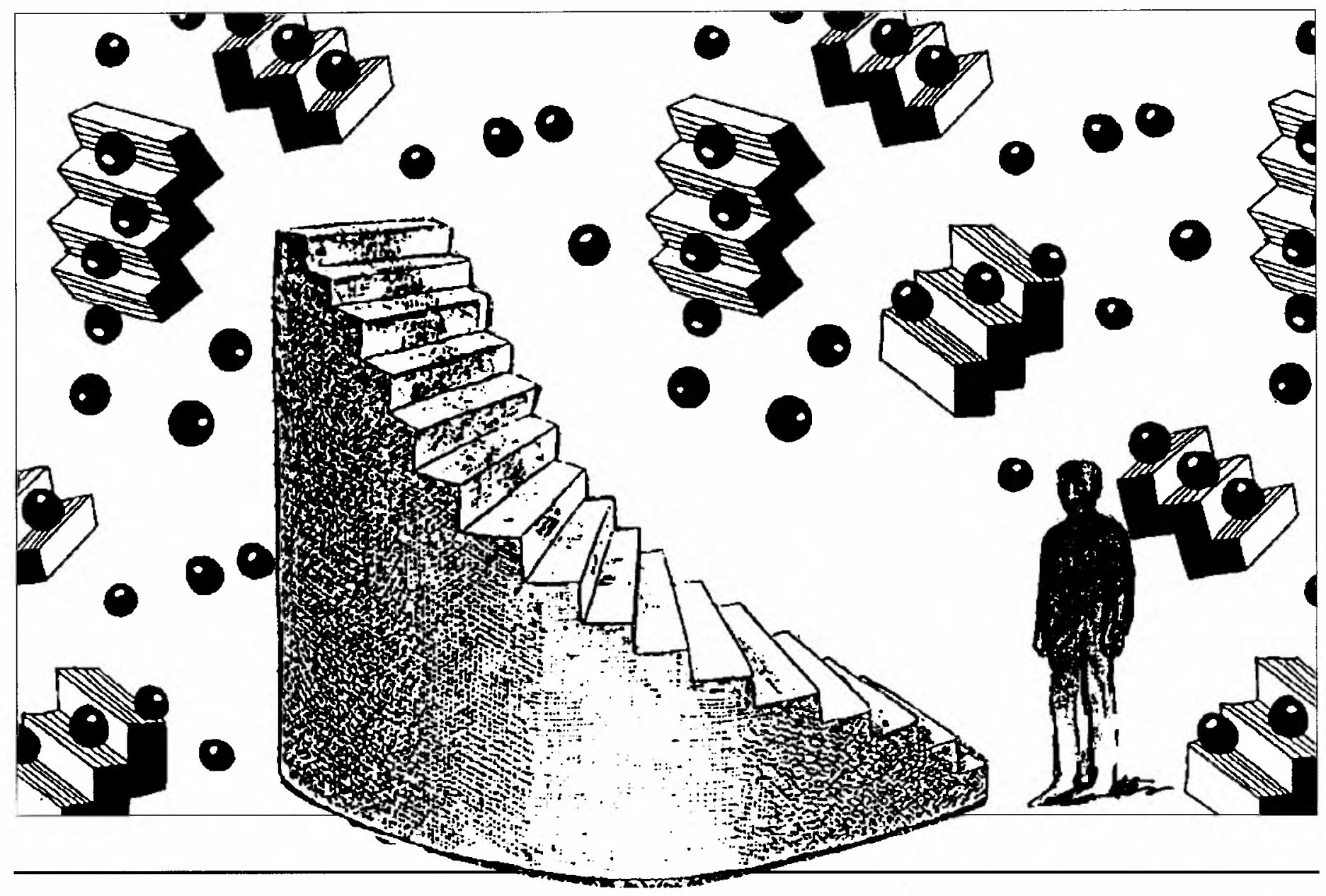

Marcelo Machado Teixeira de Andrade Mestrando em Administração de Empresas pela USP.

* RESUMO: As mudanças da conjuntura nacional e internacional pressionam a mudança de sistemas tradicionais que já não fornecem boas respostas às demandas desse ambiente. O trabalhador do futuro exigirá maior autonomia, envolvimento e participação; por sua vez, a empresa do futuro deverá ser mais flexivel e zelar pela qualidade dos seus produtos, com custos competitivos. Em conseqüência, o sistema de recompensa terá que sofisticar-se e ampliar seu campo de atuação. Salário baseado nas habilidades e/ou no desempenho da equipe, participação nos resultados e nas decisões do sistema de recompensa, benefícios flexíveis e compensação total são alguns dos conceitos aqui apresentados.
* PAlAVRAS-CHAVE: Ambiente, múltiplas habilidades, equipe, participação e compensação total.

* ABSTRACT: Changes in the domestic and foreign environment call for the transformation of traditional systems which no longer respond well to the environment. The worker of the future will demand greater autonomy, involvement and participation; companies, on the other hand, will be more flexible, and more cost and quality-oriented. Consequently, compensation systems will have to be broader in scope and more sophisticated. Salaries based on skills and team performance, profitsharing and participation in decisions on compensation, more flexible benefit plans, and total compensation are some of the concepts presented here.

* KEY WORDS: Environment, multiple skills, team, participation, total compensation. 


\section{INTRODUÇÃO}

A compensação em recursos humanos não é um fim mas, meio, para se alcançarem objetivos tanto da organização quanto das pessoas que nela trabalham. Por isso, a melhor maneira de se discutir o sistema da recompensa no futuro é colocá-lo no contexto da gestão empresarial e do trabalhador do futuro: é sob essa perspectiva que o presente texto pretende tratar o tema da compensação em recursos humanos.

\section{O NOVO CONTEXTO DO SISTEMA DE RECOMPENSA}

A empresa do futuro corresponderá à nova dinâmica da conjuntura mundial. Participação, integração, concorrência internacional, tecnologia, qualidade, conhecimento, informação e velocidade de mudança são algumas das palavras-chave da nova ordem mundial.

O modelo taylorista, ao atomizar as tarefas e separar a concepção da execução, limita a contribuição de seres humanos inteligentes e dotados de vontade ao mero exercício de uma função simples e repetitiva.

Nesse sentido, o modelo empresarial japonês, no que tem de mobilizador do potencial humano, indica-nos um caminho a seguir. Exemplos dos resultados dessa abordagem não faltam. Apenas para citar um: os empregados do Grupo Toyota, em um único ano, formalizaram 570.000 sugestões, das quais 500.000 foram implementadas ${ }^{1}$. Não que acreditemos que mobilizar o pessoal se resuma a espalhar caixas de sugestão pelas instalações da empresa; também não advogamos que a administração japonesa seja o paradigma da administração do futuro. Trata-se apenas de apresentar um fato que, pelo seu impacto na economia e na organização das empresas de todo o mundo, parece ser portador de futuro.

O conceito de mobilização, que destacamos como uma característica importante da empresa do futuro, é uma das vertentes práticas da participação; ao mesmo tempo, está em estreita conexão com uma nova concepção de autoridade, concepção esta que nada tem a ver com a velha caricatura do chefe que sabe e manda, e dos executantes que executam, em silêncio, o que lhes foi mandado. $O$ gerente deve ser cada vez mais, como postulam Naisbitt e Aburdene ${ }^{2}$, um facilitador. Porque - es sa é a idéia central - um gerente coordena e estimula pessoas inteligentes, com vontade própria, com potencial criativo, capazes de trabalhar em equipe e de adaptar-se a novos trabalhos, ambientes e situações; somem-se a esses traços inerentes à natureza humana a experiência de trabalho, o nível de educação cada vez maior e a própria vivência de participação social do indivíduo fora do seu local de trabalho, e obtemos como resultado um perfil do trabalhador do futuro.

É de justiça - e o contrário, além disso, seria um desperdício - dar a esse indivíduo uma função compatível com a sua capacidade.

$\mathrm{O}$ trabalho em equipe, a capacitação em múltiplas tarefas e os círculos de qualidade em suas versões mais modernas podem ser algumas das respostas a essa exigência de cunho humano e organizacional. A própria necessidade de maior flexibilidade e agilidade da empresa para adaptar-se (e se possível adiantar-se) às mudanças do ambiente apontam para tais soluções.

Um artigo publicado na revista Business Week ${ }^{3}$, sobre as principais tendências das empresas americanas para os anos 90, arrola conceitos como flexibilidade, trabalho em equipe e habilidades múltiplas; serão, a nosso ver, conceitos empresariais importantes da próxima década.

A adoção de produção flexível, como postula o citado artigo, freqüentemente é acompanhada de práticas de trabalho mais fluídas que enfatizam mais a iniciativa e a resolução de problemas do que o desempenho mecânico e repetitivo.

A produção baseada em equipe começa a substituir o sistema tradicional em indústrias como a aeroespacial, automobilística, de equipamentos elétricos e outras. Um exemplo entre tantos é a da fábrica da General Eletric Co., em Salisbury, E.U.A., que combina trabalho em equipe com flexible automation e outros sistemas computadorizados 4 .

E um exemplo extremo é o da montadora da Volvo em Uddevalla, Suécia, cuja organização é ainda menos ortodoxa do que da famosa fábrica de Kalmar, também da Volvo. Em Uddevalla, as equipes gerenciam-se praticamente sozinhas, cuidando da programação, controle de qualidade, contratações e outras funções normalmente exercidas por superiores. Linha de montagem, atomização das tarefas e supervisão cerrada são conceitos estranhos a esse novo sistema de trabalho ${ }^{5}$.

Claro está que inovação no processo de trabalho como as de Uddevalla estão a anos-luz da média das indústrias como um todo. Mas retratam uma tendência que, de forma mais ou menos intensa, já está presente em muitíssimas empresas de todo o mundo. E não só no nível de fábrica: tomado de forma ampla, essa nova concepção de trabalho em equipe e de maior autonomia e espaço para as pessoas no trabalho pode ser encontrada em setores tão diversos quanto pesquisa, propaganda, 


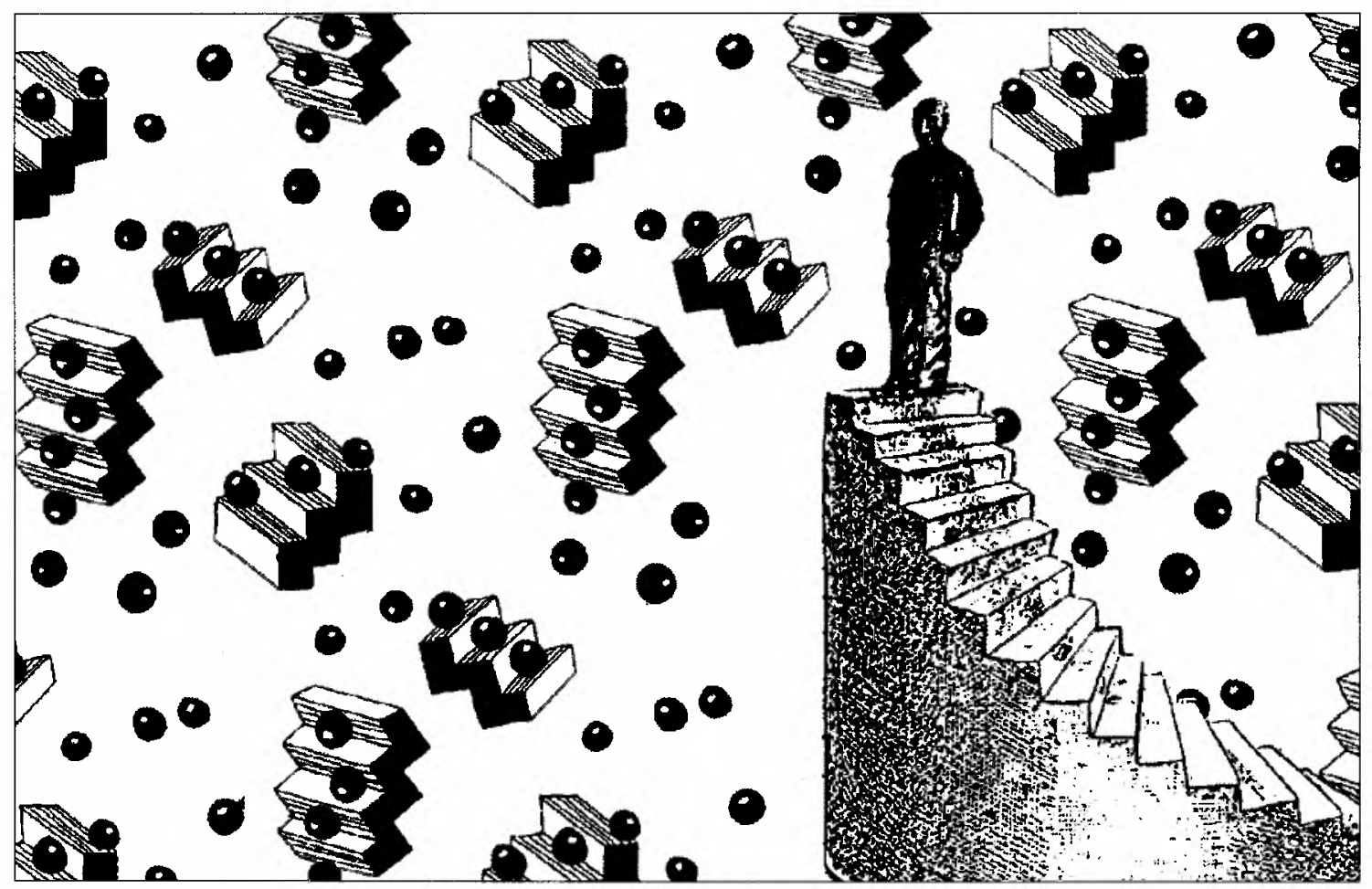

prestação de serviços em geral e mesmo em escritórios administrativos.

Em suma, um perfil da empresa do futuro deveria incluir as seguintes notas: maior participação, nova concepção de autoridade, zelo pela qualidade, flexibilidade e velocidade de mudança. Obviamente, não temos a pretensão, e nem a intenção, de esgotar as características distintivas da organização do futuro; apenas destacamos aquelas que parecem contribuir mais fortemente para mudanças no sistema tradicional de recompensa.

Do lado do trabalhador e da organização do trabalho, poderíamos esperar a emergência e consolidação das seguintes características: trabalho em equipe, múltiplas habilidades, maior autonomia e maior envolvimento na organização, o que significaria compartilhar tanto resultados como responsabilidades (pela qualidade, pelos custos, pelos prazos etc.).

Esboçado um novo contexto da organização e do trabalho, tentemos deduzir sua repercussão no sistema de recompensa.

\section{A AMPLIAÇÃO DO CAMPO DO SISTEMA DE RECOMPENSA}

Junto às necessidades de manutenção do equilíbrio interno e externo, objetivos tradicionais da administração de salários, surgem outras necessidades que o sistema de compensação em recursos humanos pode respaldar ou incentivar: a qualificação dos traba- lhadores para exercerem diversas funções, o trabalho em equipe e a participação.

Uma abordagem compatível com a multiqualificação é a do salário baseado nas habilidades. Como observa Lawler 6 , a idéia de pagar uma pessoa conforme seus atributos $\mathbf{e}$ não em virtude do cargo que ocupa não é nova e pode ser encontrada em muitas organizações (por exemplo: universidades, escritórios de advocacia, laboratórios de pesquisa). Embora bem menos freqüente, há casos de aplicação da idéia para cargos de nível mais baixo, como o da fábrica da General Foods em Topeka. A posterior análise dessa experiência leva a crer que o novo plano de pagamento contribuiu tanto para a eficácia organizacional quanto para uma alta qualidade de vida no trabalho. "A eficácia organizacional parece ser devida à flexibilidade da força de trabalho, à perspectiva mais ampla dos trabalhadores sobre como funciona a fábrica e ao indice mais baixo de "turnover". A alta qualidade de vida parece ter sido alcançada porque o plano reforça o espirito de crescimento e desenvolvimento pessoal e produz taxas de salário que são percebidas como eqüitativas"

É claro que os planos de pagamento baseados nas habilidades têm seus problemas e uma alternativa da resposta a pelo menos dois dos novos dilemas organizacionais: a necessidade de maior flexibilidade da produção e a exigência dos trabalhadores por mais espaço para darem vazão ao seu potencial. limitações. Não deixam de ser, entretanto,
6. LAWLER III, Edward E. Pay and organizational development. Reading, Mass., Addison-Wesley, 1981, p.65.

7. Idem, ibidem, pp. 66-7. 
Tanto o exercício de múltiplas funções (suposta a prévia capacitação) quanto o trabalho em equipe reclamam, a nosso ver, uma descrição de cargos mais genérica do que a que hoje normalmente se utiliza. A descrição tradicional, ao procurar retratar com exatidão as funções de um determinado cargo, constrange-o a esse retrato. Por que impor-se o esforço de contornar os obstáculos de uma descrição rígida, quando o que se pretende é mais flexibilidade e menos limitação ao potencial do trabalhador? Sem querer subestimar as dificuldades de ordem técnica, legal e sindical, acreditamos ser possível mudar o padrão da descrição de cargos.

E tendo em conta tantas situações de trabalho em equipe que exigem especial mobilidade e versatilidade das pessoas, faz sentido repensar o próprio conceito de cargo. $\mathrm{Mu}$ danças organizacionais que incluem a diminuição do número de cargos e de níveis hierárquicos, comuns hoje em dia, são um reflexo desse questionamento.

Outro velho axioma, o de que o gerente deve necessariamente ganhar mais que seus subordinados, parece perder sua condição de universalmente aplicável. Whitney, discutindo os rumos que a compensação poderá tomar nos anos 90, também critica essa tese. Partindo do pressuposto de que a diferentes estruturas organizacionais correspondem diferentes formas de remuneração, e pensando em empresas de alta tecnologia, onde o esforço criativo é fundamental, esse autor afirma que "o lider em qualquer projeto freqüentemente é aquele com a maior especialização técnica, independentemente de sua posição (...) A responsabilidade pela qualidade dos resultados técnicos recai primariamente sobre os técnicos", já o gerente "é um facilitador e um recurso para aqueles que planejam, dirigem e controlam seu proprio trabalho. É perfeitamente justificável que o técnico possa ganhar mais do que o gerente a quem ele se subordina"s.

Ainda sobre essa questão da diferença salarial entre gerentes e técnicos, podemos acrescentar um conhecido problema: o do técnico que, querendo ganhar um salário mais alto em uma organização que privilegia a hierarquia, precisa aspirar a cargos gerenciais que, se atingidos, com frequiência transformam bons técnicos em gerentes medíocres. $\mathrm{O}$ uso da carreira em " $y$ " é uma das formas de minimizar esse problema, oferecendo possibilidade de ascensão em uma carreira técnica.

No mesmo artigo acima citado, Whitney

8. WHITNEY, James L. "Pay concepts for the 1990's, part 1". Compensation and Benefits Review, marçoabril, 1988, p. 42. cutivos separados do resto da organização. Como conseqüência, pode acontecer que esforços para gerar trabalho em equipe que envolva tanto gerentes como não-gerentes sejam seriamente inibidos. Além do que os benefícios especiais para executivos podem reforçar o sistema de valores que incentiva bons técnicos a tornarem-se maus gerentes.

Uma nova forma de compensação, associada ao trabalho em equipe, é pagar pelo desempenho da equipe como um todo. São bem conhecidas as dificuldades de se relacionar pagamento a desempenho. No entanto, quando o marco de referência é a equipe e não o indivíduo, alguns dos problemas são minimizados. Por exemplo, o da avaliação de desempenho, na medida em que é bem menos complicado medir os resultados de um grupo do que de uma pessoa tomada isoladamente. Evita-se, também, incentivar o excessivo individualismo, prejudicial ao grupo e mesmo à organização como um todo.

Sem deixar de ter seus próprios problemas, como o desincentivo ao esforço diferenciado, pode-se inserir a remuneração pelo desempenho da equipe no rol das novas alternativas em compensação. Nova, do mesmo modo que o pagamento baseado nas habilidades, ao menos no sentido de que ainda é muito pouco usada.

\section{PARTICIPAÇ̃̃o E COMPENSAÇÃO}

A participação, um dos novos valores da sociedade, deverá marcar profundamente a empresa do futuro. Do ponto de vista da compensação, esse novo valor pressiona o surgimento de novas formas de remuneração e de condução do plano salarial.

$\mathrm{O}$ "ESOP", employee stock-ownership plan, materializa a idéia do empregado-acionista. E um plano já bastante difundido nos Estados Unidos, embora haja críticos que relacionem sua popularidade aos incentivos fiscais que $o$ acompanham.

Mais freqüentemente discutida é a participação nos lucros, independentemente de participação acionária. Trata-se de um campo aberto para a criatividade, já que não há uma resposta única que solucione o como dividir, e nem suficiente experiência acumulada.

Quanto à forma de condução do plano de remuneração, a tendência é tornar-se mais participativo. Lawler considera que em muitas empresas os sistemas de compensação são desenhados, implementados e administrados de maneira autoritária, de cima para baixo. "Como conseqüência, pondera o autor, o nível de aceitação dos sistemas de compen- 
sação é freqüentemente baixo, e seu desenho não poucas vezes deixa de levar em conta importantes informações sobre as preferências e desejos daqueles que de fato o suportarão. Sob certas condições, a participação nas decisões do sistema de recompensa é uma abordagem que produzirá melhor compreensão do sistema, um sistema melhor e um alto comprometimento para implementá-lo" ${ }^{\prime \prime}$. As tais condições, às quais Lowler alude, referem-se a características organizacionais particulares, papel das mudanças no sistema de pagamento dentro de um esforço de desenvolvimento organizacional e outros tantos fatores organizacionais cujo comentário fugiria do escopo da nossa discussão.

\section{FLEXIBILIDADE}

Qualidade, inovação, flexibilidade e conhecimento do mercado são atributos que, embora não sejam novidade, merecem cada vez mais atenção dentro das empresas. Estreitamente ligados a eles, estão os recursos humanos. Verdadeiras fortunas são investidas em treinamento e desenvolvimento de pessoal, visando a formar um quadro capaz de zelar pela qualidade e pela inovação, que seja flexível e que conheça o mercado. Com isso ganha importância a manutenção dos recursos humanos, para o que salários e benefícios contribuem de forma destacada.

Diante dos novos desafios impostos pela empresa e pelo trabalhador do futuro, os planos de compensação se sofisticam. Dois exemplos que poderíamos acrescentar aos já citados até aqui são os Programas de Benefícios Flexíveis e a Compensação Total.

Há um certo número de circunstâncias pessoais, como idade, sexo, estado civil e número de crianças, que influenciam a preferência do indivíduo por dados benefícios. Como Lowler observa, pessoas em diferentes situações de vida têm diferentes necessidades. Considerando os tradicionais pacotes que não levam em conta essas diferenças, é de se esperar que muitas pessoas não tenham os benefícios adicionais que quereriam; o que significa que muitos pacotes de benefícios não dão um retorno positivo sobre seus custos. "O que as organizações estariam fazendo seria pegar alguma coisa de valor (dinheiro), convertê-lo em algo de menos valor (beneficio), e então tentar usar essa 'mercadoria' para atrair e reter os empregados" ${ }^{10}$. Uma maneira de equilibrar melhor essa oferta e demanda de benefícios é o Plano de Benefícios Flexíveis ou Cafeteria Style. Por esse plano, os empregados são informados de quanto a empresa pretende gastar com cada um deles em termos de compensação e têm a oportu- nidade de decidir como receberão esse dinheiro: se tudo em dinheiro ou parte em benefícios, os quais, por sua vez, estariam à disposição como produtos à venda nas prateleiras de um supermercado. "Um plano de beneficios flexíveis deixa claro aos empregados exatamente quanto a organização está despendendo para compensá-los, e assegura que o dinheiro será gasto somente nos beneficios que os empregados quiserem"1.

A implantação de uma abordagem Cafeteria Style, obviamente não está isenta de dificuldades, nenhuma delas, contudo, insuperável. E como o escopo do plano é amplo, há espaço para soluções intermediárias. Além disso, conforme se ganhe experiência de sua aplicação e com a conseqüente criação de uma memória de dados sobre preferências por benefícios, a manutenção do plano tornase mais fácil.

Já a compensação total é o uso simultâneo de diversas formas de recompensa. Podem existir um sistema de benefícios flexíveis, um salário base, recompensa pelo desempenho, participação nos lucros, ajustes salariais baseados nas habilidades, recompensa pelo serviço (em vista, por exemplo, do tempo de casa ou do tempo na área), recompensa pelo sacrifício (em virtude de viagens, mudança de cidade etc.), prêmios especiais (como viagens de férias, licenças etc.) e o que mais a criatividade puder conceber. É claro que não é preciso incluir todas as formas conhecidas de salários e benefícios. Há limites a partir dos quais um acréscimo de complexidade tornase inadministrável.

Ao mencionar a compensação total, pretendemos simplesmente destacar que as muitas formas de recompensa não são necessariamente excludentes, e que a criação de um plano de compensação eficaz não deve se ater necessariamente ao que já existe.

\section{CONCLUSÃO}

Apresentamos neste texto uma série de idéias dentro do campo da compensação, procurando adotar uma postura prospectiva. A maioria dos conceitos já são bem conhecidos, mas, no geral, muito pouco praticados. Os "planos de sempre" ainda imperam nas empresas.

Para o trabalhador do futuro, na empresa do futuro, nada melhor do que um sistema de recompensa do futuro. Embora velhas fórmulas por vezes possam ser suficientes para resolver os novos problemas das organizações, a busca da inovação sempre deverá estar presente.]
9. LAWLER III, Edward E. Op. cit., p. 26 .

10. Idem, ibidem, p. 73.

11. Idem, ibidem, idem. 